\title{
Aconselhamento na testagem anti-HIV no ciclo gravídico-puerperal: o olhar da integralidade
}

\author{
Counseling in HIV testing \\ in the pre and post labor periods: the look of the integrality
}

Ana Jaqueline Santiago Carneiro ${ }^{1}$

Edméia deAImeida Cardoso Coelho ${ }^{2}$

${ }^{1}$ Curso deEnfermagem, UniversidadeEstadual do SudoestedaBahia. Ruajosé M oreira Sobrinho $\mathrm{s} / \mathrm{n}$, Jequiezinho. 45206-190 Jequié $B A$.

enfjaqueline@hotmail.com

2Departamento de

Enfermagem Comunitária,

Escola de Enfermagem,

Universidade Federal da

Bahia.
Abstract The sorology for HIV in woman and rapid HIV testing in maternity hospitals must be carried with pre and pos-test counseling. H owev$e r$, it has been observed that the counseling has not been accomplished by many health professionals, who give more importance to the prophylactic measures which intend to prevent vertical transmission. The objective of this qualitative study is to investigate how women evaluate the health care received during the HIV testing at pre and post-labor periods. For this paper the look of woman about counseling in the process of HIV testing was cut. We used gender and integrality as analytic categories. The technique used to collect data was the semi-structured interview, carried out in women seen at the CTA for diagnostic conclusion. The testing lost its specificity through its inclusion in the clinical practice as a routine without a counseling in any stages of the care during pre and post labor periods. The relationship between users and professionals reflect power mechanisms that compromise the autonomy of women, distancing the care from the perspective of the integrality.

Key words HIV/aids, Vertical transmission, Rapid HIV testing, Counseling, Integrality
Resumo A sorologia para HIV em mulheres no pré natal e os testes rápidos anti-HIV em maternidade devem ser realizados com aconsel hamento préepós-teste. $\mathrm{N}$ a prática, observa-sequeessenem sempre é realizado, predominando o cumprimento de procedimentos técnicos destinados a prevenir a transmissão vertical. 0 objetivo deste estudo foi analisar o cuidado profissional a mulheres que tomaram conhecimento da positividade para 0 HIV durante 0 trabalho de parto ou puerpério. Trata-se de estudo exploratório de natureza qualitativa, utilizando como categorias analíticas gê nero e integralidade. Participaram do estudo doze puérperasusuárias deum centro de referência para HIV/aids, em Salvador (BA). Foi recortado para esteartigo o ol har das mulheres sobreo aconselhamento no processo de testagem para o HIV. Os re sultados foram produzidos a partir de entrevista semiestruturada e analisados pela técnica de análise de discurso segundo Fiorin. A análise revelou que a testagem anti-HIV foi incorporada à prática clínica sem aconselhamento em nenhuma das etapas da atenção ao ciclo gravídico- puerperal, na realidade investigada. As relações entre profi ssionais e usuárias refletem mecanismos de poder que comprometem a autonomia das mulheres, distanciando o cuidado da perspectiva da integralidade. Palavras-chave HIV/aids, Transmissão vertical, Teste rápido, Aconselhamento, Integralidade 
Introdução

Quando da identificação dos primeiros casos de aids, o grupo populacional mais atingido era 0 de homens homo e bissexuais mas, atualmente, o quadro da epidemia é marcado pela heterosse xualização, interiorização e feminilização ${ }^{1}$. 0 número de mulheres infectadas aumenta rapidamente entre as heterossexuais casadas, com parceiro único e não-usuárias de drogas, sendo a relação sexual a principal via de transmissão do HIV para essas mulheres.

Na década de noventa do século $X X$, as faixas etárias que concentraram os maiores percentuais de casos de aids em mulheres foram aquelas entre 25 e 29 anos eentre 30 e 34 anos, ou seja, as mulheres têm sido atingidas em plena idade reprodutiva ${ }^{2}$. 0 maior envolvimento da mulher na dinâmica da epidemia levou a um mai or interesse pel as mulheres grávidas e despertou a atenção de estudiosos (as) na área da saúde devido à dificuldade do diagnóstico precoce e ao risco de transmissão materno-fetal.

0 protocolo 076 do Aids Clinical Trial Group (PACTG 076), de 1994, comprovou que o uso da zidovudina (AZT) reduz a transmissão vertical do HIV em $67,5 \%$ quando usado durante a gestação, trabalho de parto e pelos recém-nascidos que foram alimentados exclusivamente com fórmula infantil2.

No Brasil, a partir do ano de 1996, a Coordenação N acional deDST eAids estabeleceu como meta o controle da transmissão vertical do HIV e iniciou a divulgação de ações para a sua prevenção. A partir de 2000 , a vigilância de mulheres grávidas infectadas e crianças expostas tornouse compulsória, através da portaria n 993/GM².

No ano de 2001, o M inistério da Saúde estabeleceu as recomendações para profilaxia da transmissão vertical do HIV eterapia antirretroviral em gestantes. No ano de 2002, foi criado 0 Projeto Nascer, que tem como objetivo possibilitar a diminuição do número de crianças infectadas por meio da oferta do teste rápido a todas as parturientes que não apresentassem sorologia prévia para HIV, bem como oferta do tratamento quimioprofilático da transmissão vertical².

Para a mulher que recebe o resultado de teste rápido positivo durante 0 trabalho de parto, como veremos ainda nesse estudo, há um impacto emocional muito grande, mesmo considerando-se o caráter não definitivo, uma vez que é um exame de triagem. N essas situações, somase às alterações físicas e emocionais do trabal ho de parto a possibilidade de infecção pelo HIV e da consequente possibilidade de transmissão para o (a) filho (a). Para reduzir esse impacto, é necessário encontrar formas adequadas de cuidar das mulheres que apresentam teste rápido positivo, buscando-se estabelecer uma comunicação que lhes permita esclarecer dúvidas efazer suas próprias escolhas, evitando a imposição de normas institucionais.

Os manuais e protocolos governamentais preconizam a realização da sorologia para HIV na gestação e do teste rápido no trabalho de parto para as que não realizaram o exame na gestação, ressaltando a importância do aconselhamento antes e após o resultado do exame, independentemente do seu resultado. De acordo com o M inistério da Saúde, o aconsel hamento consiste em U m processo de escuta ativa, individualizada e centrada na pessoa. Pressupõe a capacidade de estabelecer uma relação de confiança entre os interlocutores, visando o resgate dos recursos internos do indivíduo para que ele mesmo tenha possibilidade de reconhecer-se como sujeito de sua própria saúde e transformação ${ }^{2}$.

0 aconselhamento favorece $a$ atenção integral e contribui para que as pessoas participem ativamente do processo de promoção da saúde, prevenção e tratamento das DST/HIV/aids. No aconselhamento por ocasião do teste rápido, deve-se reafirmar o caráter voluntário e confidencial da testagem, indicar o motivo, trocar informações sobre os sistemas de testagem ejanela imunológica, trocar informações sobre o significado e impacto dos possíveis resultados, enfatizar a diferença entre a infecção pelo HIV e aidse reforçar a necessidade da adoção de práticas seguras frente ao HIV, como uso de preservativo nas relações sexuais, uso de seringas e agulhas descartáveis para usuários de drogas injetáveis e sexo sem penetração ${ }^{3}$.

Os exames anti-HIV, ainda que necessários à saúde da criança e da mulher, devem respeitar o livre arbítrio da gestante/parturiente para a sua realização, sendo o aconselhamento etapa do processo de cuidado que, adequadamente realizado, permite à mulher assumir atitude favorável à realização do exame, devendo-lhe ser garantido suporte emocional por ocasião da informação do resultado positivo e nos momentos subsequentes.

Em meio à fragilidade emocional comumente presente nas mulheres durante 0 trabalho de parto, temos observado na nossa prática profissional em uma maternidade pública que o teste rápido anti-HIV vem sendo utilizado sem necessariamente ocorrer solicitação prévia à mulher 
ou adequado aconsel hamento, ferindo o direito de informação e orientação das usuárias frente à testagem.

Observamos também que as ações de saúde posteriores à comunicação de resultados positivos estão focalizadas no cumprimento de procedimentostécnicos destinadosà profilaxia da transmissão vertical, como a utilização de AZT endovenoso durante o trabalho de parto, a suspensão da amamentação, a utilização de AZT via oral pelo recém-nascido e o encaminhamento para a realização de exames que visam à conclusão do diagnóstico. Assim, subestima-se a multiplicidade de sentimentos que acompanha a mulher no processo de enfrentamento do problema.

Diante dessas observações empíricas, decidimos por uma investigação científica com o obje tivo de analisar o cuidado profissional a mulhe res com teste rápido positivo para HIV a partir do olhar demulheres quetomaram conhecimento da positividade durante 0 trabalho de parto ou puerpério. No tocante ao aconselhamento, foi resgatada sua realização junto às puérperas desde o pré-natal, sendo divulgada neste artigo a categoria empírica referenteao processo deaconselhamento nos períodos prée pós testagem antiHIV no ciclo gravídico-puerperal.

\section{M etodologia}

\section{Caracterização do estudo}

Trata-se de um estudo do tipo exploratório com abordagem qualitativa, tendo integralidade e gênero como eixos teóricos. A integralidade busca a superação do modelo fragmentário do cuidado à saúde, o que prescinde de uma reflexão sobre o modo como vêm sendo desenvolvidas as práticas. N essa perspectiva, 0 acolhimento, 0 vínculo e a responsabilização são aspectos norteadores das relações profissionais/usuários (as), tendo o diálogo, a escuta ativa de necessidades e a valorização do contexto em que as de mandas em saúde são geradas como condições para que se estabeleça uma relação entre sujeitos ${ }^{4,5}$. Deve ser tomada não como um conceito, mas como um ideal regulador, um devir e, embora não seja plenamente atingível, é algo que devemos sempre buscar 6 .

No tocantea gênero, esteé" um elemento constitutivo de relações sociais baseado nas diferenças percebidas entre os sexos e o gênero é uma forma primeira de significar as relações de poder ${ }^{7 \prime}$. A noção de gênero é também constitutiva da organização social, das relações de poder e de dominação/subordinação que são estabelecidas em cada cultura, baseadas na dicotomização entre masculino e feminino. Os papéis de gênero variam de acordo com a cultura e são influenciados por questões de raça, classe, idade, circunstâncias históricas e econômicas.

Historicamente, a função reprodutiva tem sido concebida como primordial para o sexo feminino e a organização dos serviços de saúde dá-se segundo essa concepção, subestimando-se os demais aspectos da vida das mulheres. Asconstruções sociais em torno dos papéis que devem ser exercidos por homens e mulheres eem torno do que cada sexo representa na sociedade influenciam sobremaneira o direcionamento das políticas de saúde ${ }^{8}$.

No Brasil, a saúde da mulher foi incorporada às políticas públicas de saúde nas primeiras décadas do século XX, sendo, nesse período, limitada às demandas relativas à gravidez $e$ ao parto. Os programas materno-infantis implantados nesse período reduziam seu papel social à função reprodutiva, vendo a mulher apenas como mãe e cuidadora da saúde da família, preconizando atenção nos períodos do prénatal, parto e puerpério ${ }^{9}$.

A preocupação excessiva com a função reprodutiva da mulher teveforteinfluência na conformação das políticas públicas desaúde, havendo a partir dos anos oitenta partici pação intensa do movimento feminista na reivindicação depolíticas que valorizassem as especificidades do ciclo vital feminino.

Como resposta do Estado à luta das mulheres, em 1984, foi criado o Programa de Atenção Integral à Saúde da Mulher (PAISM ). Este representava uma tentativa de superação do modelo anterior de atenção à saúde da mulher, fragmentado e desarticulado com outras ações do governo federal e com baixo impacto nos indicadores de saúde. O PAISM incorporava princípios que davam sustentação à formulação do Sistema Ú nico de Saúde (SUS), como descentralização, hierarquização, regionalização, equidade e integralidade $^{10}$.

Esta proposta apresentou um avanço em relação às políticas de saúde anteriores orientadas pelo Programa de Saúde Materno-infantil implantado na década de setenta, pois preconizava uma assistência à mulher que a atingisse em todas as fases de sua vida.

A Política Nacional deAtenção Integral à Saúde da Mulher, de 2004, amplia a perspectiva do PAISM , mantendo em seus fundamentos a defe- 
sa da reorientação das práticas profissionais no sentido da atenção integral. Para isso, valoriza as questões de gênero como fatores que interferem no acesso das mulheres aos serviços de saúde e nos padrões demorbidadeemortalidade do sexo feminino.

No âmbito da saúde da mulher, a integralidade é considerada por Coelho et al. ${ }^{11}$ como a concretização de práticas de atenção que garantam 0 acesso das mulheres a ações resolutivas, construídas segundo as especificidades do ciclo vital feminino e do contexto em que as necessidades são geradas. N esse sentido, o cuidado deve ser permeado pelo acolhimento e escuta sensível de suas demandas, valorizando-se a influência das relações de gênero, raça/cor, classe e geração no processo de saúde e de adoecimento das mulheres.

Assim, práticas orientadas pela integralidade qualificam o cuidado, representando perspectiva que possibilita a compreensão das necessidades dos sujeitos, bem como a adoção de atitudes que permitam aproximar as ações profissionais das soluções que as pessoas esperam encontrar para seus problemas de saúde. Para que o (a) profissional oriente suas práticas pelo princípio da integralidade, é preciso estar constantemente buscando ampliar sua visão de mundo e reconhecendo a multidimensionalidade dos sujeitos da atenção.

\section{Trajetória metodológica}

Constituíram sujeitos do estudo mulheresque haviam realizado teste rápido para HIV durante o trabalho de parto e obtiveram resultado positivo. Foram identificadas no Centro de Testagem e Aconsel hamento (CTA), serviço de referência estadual em prevenção para HIV e outras infecções sexualmentetransmissíveis (IST), para onde as mulheres são encaminhadas, preferencialmente, após a alta da maternidade, para a realização dos exames confirmatórios, passando pelas etapas de aconselhamento pré e pós-teste.

Fizeram parte do estudo mulheres que concordaram em participar e assinaram o termo de consentimento livre e esclarecido, elaborado segundo a resolução n 196/96 do Consel ho Nacional de Saúde, que trata de pesquisa envolvendo seres humanos. 0 projeto de pesquisa foi aprovado por Comitê de Ética em Pesquisa segundo o parecer CEP/M CO/U FBA no 97/2006.

Foi escolhido o puerpério como período para entrevista por considerarmos que, no período de internamento, as mulheres ainda estão vivendo 0 impacto do resultado positivo efragilizadas emo- cionalmente, contraindicando a realização das entrevistas. Passado algum tempo, apresentam melhores condições de avaliar a qualidade do cuidado que lhes foi prestado. Constituiu critério de exclusão o diagnóstico prévio confirmado para HIV, ou seja, durante a gravidez ou antes dela.

As entrevistas foram realizadas no período de julho a setembro de 2006. As mulheres foram entrevistadas em período anterior ao da conclusão do diagnóstico, antes do aconselhamento pré-teste inicial. Esse critério foi adotado tendo em vista que, até concluírem todo o fluxograma estabelecido para o diagnóstico definitivo, as usuárias passam por diversas etapas de aconseIhamento individual prée pós-teste, além deum aconselhamento coletivo. Isso faz com que, ao final desse processo, obtenham maior esclarecimento em relação ao HIV/aids. Como o cuidado investigado referia-se àquele que foi prestado na maternidade, ao entrevistarmos mulheres que tiveram seguimento posterior, suas respostas poderiam não retratar exatamenteo cuidado que receberam na maternidade.

O material empírico foi produzido por meio da técnica de entrevista semiestruturada.

Foram entrevistadas doze mulheres. As entrevistas foram gravadas e transcritas na íntegra, com exceção de duas que não autorizaram o uso do gravador, sendo as respostas registradas manualmente. As entrevistas foram realizadas em consultório, garantindo-se privacidade e sendo utilizados nomes fictícios escolhidos pelas próprias participantes para a sua identificação na pesquisa.

Seguindo o que é preconizado por Fiorin ${ }^{12}$ para formulação das categorias empíricas, foram feitas leituras sucessivas do texto inteiro, tentando localizar todas as recorrências, isto é, figuras, elementos concretos e temas, elementos abstratos, segundo traços semânticos. Feita a depreensão dos temas centrais, os dados foram agrupados em blocos de significação que originaram a categoria empírica apresentada neste artigo, sendo analisada em articulação com a literatura pertinente.

\section{Ausência de aconselhamento na testagem para HIV negando a autonomia das mulheres}

A ausência de autonomia das mulheres no processo decisório de testagem para o HIV constituiu o tema de maior abstração extraído do material empírico relativo à pesquisa em foco. Segundo Ribeiro ${ }^{13}$, o termo autonomia, do gre- 
go autos (próprio) e nomos (regra, autoridade ou lei) foi utilizado pela primeira vez para se fazer referência ao autogoverno das cidades-Estado independentes. $\mathrm{N}$ a década de setenta, surgiu o Relatório Belmont, que foi utilizado pela biomedicina na concessão de poder para se tomar decisões em assuntos médicos.

A autonomia é um direito protestativo, que pode ser exercido sem a aprovação de terceiros, de modo que uma pessoa com autonomia plena tem os mesmos poderes e garantias que um Estado: autodeterminação. Segundo a autora, as relações paternalistas no cuidado à saúde dificultam a concretização desse direito. Porém, a legislação brasileira vem procurando abrir espaço para a transformação dessas relações, incluindo o princípio da autonomia, de modo que o (a) profissional de saúde deixe de ser soberano(a) e a assistência seja mediada pelo diálogo, assegurando-se o direito à informação e a decisões conscientes, incluindo o consentimento livree esclarecido ${ }^{13}$.

Neste estudo, a negação do princípio da autonomia traduz a incidência do poder de profissionais de saúde sobre as mulheres, entendendose o poder, segundo Foucault ${ }^{14}$, como aquilo que exerce repressão sobre a natureza, os indivíduos, os instintos ou uma classe, de modo que, "o poder não se dá, não se troca nem se retoma, mas se exerce". Para esse autor, os intelectuais ocupam posições sociais específicas, definidas pelo dispositivo de verdade, que consiste no conjunto das regras segundo as quais se distingue o verdadeiro do falso e se atribui ao verdadeiro efeitos específicos de poder.

Em se tratando de profissionais de saúde, a verdade é representada pelo conhecimento científico do qual dispõem. Através dele, se estabelece não só a diferenciação entre as categorias sociais detentoras e não detentoras do saber, mas também se exerce o poder das primeiras em relação às últimas, estas representadas pelos(as) usuários(as).

No Brasil, em 30 de março de 2006, o M inistério da Saúde aprovou a Carta dos Direitos dos Usuários da Saúde pela Portaria no 675/GM . 0 documento foi elaborado considerando as diretrizes da Política Nacional de Humanização da Atenção e da Gestão do SUS, em implementação pelo M inistério da Saúde desde 2003, que defende 0 atendimento acolhedor, humanizado e resolutivo para os(as) usuários(as) de saúde, bem como a promoção de mudanças de atitude em todas as práticas de atenção e gestão que fortale çam a autonomia e o direito do cidadão e da cidadã ${ }^{15}$.
Dentre as doze puérperas entrevistadas nesse estudo, cinco informaram ter realizado sorologia para HIV no pré-natal. Dessas, duas informaram não ter recebido nenhum esclarecimento por parte dos(as) profissionais e três receberam orientações superficiais quenão constituem aconselhamento, haja vista que esse consiste numa relação de diálogo e confiança entre profissional e usuário(a) que permita a este(a) tomar suas próprias decisões, após estar adequadamente informado(a). Aquelas que não foram orientadas foram sabedoras da solicitação através da leitura da requisição do exame, conforme pode ser constatado nos depoimentos a seguir: Ela só fez pedir a requisição. $N$ ão explicou nem perguntou. Eu achei que era normal, porque eu achei que a mulher grávida hoje em dia é obrigatório fazer esse exame. (Amanda)

Eu peguei a requisição evi que tinha pedido de HIV. Ela não falou nada. Pediu junto com tudo [outros exames do pré-natal]. (Nice)

A obrigação em cumprir a determinação profissional, expressa nos depoimentos em análise, retrata a submissão das mulheres ao poder institucional, que age silenciando pessoas que não participam das decisões sobre a sua vida também em outros campos da atenção. Sem a noção do direito à liberdade deescol ha euma vez incorporado que o poder pertence a quem possui 0 saber, legitimado socialmente, as mulheres aceitam incondicionalmenteo queédeterminado pelo serviço de saúde. Assim, está ausentenão somente a explicação e 0 aconselhamento, mas também qualquer tipo de questionamento por parte das mulheres. Incorporado como tal, tanto por quem decide quanto por quem obedece, as(os) profissionais se eximem da responsabilidade de investir numa relação que envolve diálogo, escuta e decisão do outro(a), garantindo, assim, a sua hegemonia nas decisões.

No tocante a resultados negativos no prénatal, momento propício para serem ressaltadas as medidas de prevenção ao HIV, também foi perdida a oportunidade de aconselhamento. Corrobora nossos dados o estudo de Feliciano e $K$ óvacs $^{16}$, que ressalta a preocupação quanto ao silêncio dos(as) profissionais em atividades educativas e de prevenção relacionadas às DST/aids promovidas para gestantes em unidades básicas de saúde. Fizeram parte do seu estudo 27 unidades, entre centros de saúde, unidades básicas e maternidades, sendo que em nenhuma delas ocorreu aconselhamento. As autoras concluem que existe pouco interesse por parte dos(as) profissionais em interagir com os(as) usuários(as) 
na construção de medidas de preven ção às DST / aids e que o modelo de organização dos serviços não tem sido capaz de atender às necessidades globais de saúde da mulher.

As entrevistadas que foram informadas sobre a necessidade de fazer a sorologia para HIV na gestação receberam orientações superficiais por parte dos(das) profissionais com relação à importância do exame, havendo preocupação, sobretudo, com a proteção da criança. A posição social dos(as) profissionais guarda coerência com a política oficial proposta pelo M inistério da Saúde; todavia, a ênfase dada à proteção da criança podetambém constituir uma estratégia de sensibilizar a mulher a não pensar na possibilidadede recusa à realização do teste, como se pode constatar nos depoimentos: Ela disse que, se desse alguma coisa, queera pra proteger a criança. ( $\mathrm{N}$ ega)

Ela falou que era importante, tanto pra mãe quanto pra criança, que toda mulher grávida tem quefazer, porquese dessealguma coisa era pra proteger a criança, que tinha tratamento. (Cláudia)

Os discursos revelam que não há preocupação com o impacto que a realização do exame pode ter na vida das mulheres e nem em conjugar as necessidades da mulher com as necessidades da criança, ou em protegê la diante das repercussões deum resultado positivo. Assim, permanece a visão da mulher como reprodutora e, uma vez cumprido o papel socialmente idealizado, secundarizam-se suas necessidades e sentimentos.

Reações das mulheres

diante da real ização da testagem anti-HIV

Uma vez incorporada a representação da função reprodutiva como o ápice da feminilidade, estar diante do comprometimento do exercício da maternidade e da sua própria vida é fonte de sofrimento. Assim, a realização de um teste antiHIV comporta variadas possibilidades de reação das mulheres, estando relacionadas também ao modo como cada mulher se percebe diante da realidade. Nesse sentido, lê-se no depoimento a seguir: Eu fiquei com medo, fiquei muito abalada, como eu tô abalada agora, pensando um bocado de coisa. Ela disse que, se desse al guma coisa, que era pra proteger a criança. (Nega)

De acordo com Remor ${ }^{17}$, alterações psicológicas podem ocorrer desde o momento em quea pessoa tem suspeita de estar infectada pelo HIV. No período que decorre da retirada do sangue atéo conhecimento do resultado do testedeHIV, existem manifestações de ansiedade provocadas pela dúvida com relação ao resultado. Essas manifestações podem incluir transtornos psicossomáticos como: cefaléia, insônia, diarréia, etc.

Pereira ${ }^{18}$ destaca que o paradoxo em torno da vida e da morte passa a fazer parte da vida de mulheres gestantes que convivem com o HIV, gerando um conflito provocado, ao mesmo tempo, pela representação de mãe, a mulher que dáa vida e que também pode trazer o risco de infecção do(a) filho(a). Esses papéis parecem ser incompatíveis, em função das construções sociais de gênero em torno da mulher e mãe como sendo a principal responsável pelo cuidado, saúde e manutenção da vida esegurança dos(as) seus(as) filhos(as). Da mesma maneira, Paiva ${ }^{19}$ constatou que, para gestantes portadoras do HIV, a soropositividadeérepresentada socialmentepela morte, enquanto que a maternidade tem caráter divino, representada socialmente pela vida, sendo que esta última se sobrepõe à condição de portadora do vírus HIV, trazendo esperança de continuidade da vida.

As condutas profissionais adotadas no prénatal se repetiram no momento de realização do teste rápido nas maternidades, o que pode ser confirmado nos seguintes depoimentos: Realmente, porque eu não soube que ela ia fazer esse teste, né ? Ela só falou assim, "Dona, a gente vai colher seu sangue pra fazer todos os exames". Aí no outro dia, ela disse: "Deu um probleminha no seu sangue". Aí eu disse: "Que problema?" Aí ela disse: "Realmente, a gentenão podedizer agora, masvocê vai ter que fazer outro teste de novo pra saber". (Nega)

Eu acho que tinha que comunicar primeiro que ia fazer o exame, mas eu acho que é porque não deu mesmo. (Nice)

No depoimento de Nega, percebe-se a dificuldade profissional de lidar com um dado novo de realidade que traz consigo a complexidade do fenômeno do HIV/aids. Ao evitar falar sobre 0 assunto, postergam-se enfrentamentos, mas não se poupa a mulher de expectativa e ansiedade, que se somam às demandas emocionais características do puerpério. Ao serem questionadas sobre quem ofereceu o teste rápido na maternidade, as mulheres apontaram o(a) médico(a) como profissional responsável pela solicitação, o que também ocorreu no pré-natal.

0 puerpério é um período de adaptação da mulher a um novo ciclo de vida e a um novo papel social, especialmente por ocasião do(a) primeiro(a) filho(a). N essa transição para a maternidade, além do cansaço físico decorrente do trabalho de parto, são mobilizados sentimentos 
como ansiedade, medo, expectativa. Soma-se a isso, no caso específico das mulheres com teste rápido positivo, a ansiedade e o choque pelo diagnóstico inesperado, trazendo a necessidade de considerar no cuidado a essas mulheres, todas as crenças, valores e representações existentes em torno da maternidade, bem como do HIV/aids.

$H$ istoricamente, o imperativo de salvar a vida das crianças mediante os interesses do Estado fez com que todos os argumentos em torno da maternidade fossem utilizados, prometendo-se a felicidade, o reconhecimento, a garantia destatus e cidadania para as mulheres ${ }^{20}$. Tal concepção passa a fazer parte dos mecanismos de construção da identidadefeminina, quefica comprometida quando não pode ser plenamente exercida, contrariando as expectativas socialmente construídas em torno do papel das mulheres ${ }^{21}$.

Nice cria justificativas de ordem prática para a falta de esclarecimento sobre o exame, inocentando os(as) profissionais. O baixo nível socioeconômico e de escolaridade dessas mulheres faz com que, mesmo em meio a situações de falta de cuidado, elas não consigam encontrar instrumentos para reagir de maneira efetiva, fazendo com que permaneçam sendo invisibilizadas nos seus direitos como mulheres e cidadãs.

0 olhar das mulheres

sobre o processo de aconsel hamento

Ao perguntarmos sobre como os(as) profissionais deveriam ter procedido com relação ao exame, as mulheres consideraram que o impacto poderia ser menor para elas caso soubessem que estariam sendo submetidas ao teste rápido. N ega eN icedemonstram preocupar-se, sobretudo, com o risco deinfecção da criança indefesa, decorrente da negligência profissional de não evitar a amamentação. As mulheres revelaram afeto, cuidado e responsabilidade materna para com os(as) filhos(as), como pode-se perceber nos seguintes depoimentos: Eu acho quea pessoa deveria avisar, né? Que tá fazendo esse exame sobre o vírus HIV, que é pra pessoa já ficar ciente. (Patrícia)

Eu acho que tinha que, em relação à criança mesmo, tinha que logo quando levou ele, tinha que avisar antes, porque aí eu não amamentava a criança. Eu acho que tinha que ter mais cuidado. (Nice)

Eu acho que desdequando a genteteve a criança e a pessoa sabe o resultado do exame, aí não deveria ter trazido a criança logo pra mim, né? Até que chegasse no outro dia edesse o leite ou alguma coisa, né? Ou então esperar o outro dia pra fazer outro exame pra ver o resultado eaí já fica sabendo se pode dar mama ou não à criança. (N ega)

A dificuldade de aconselhamento às parturientes para a realização do teste rápido decorre de obstáculos para se empreender a escuta e a comunicação e a dificuldade de abordar essa temática se dá em função de mobilizarem preconceitos e tabus tanto nos(as) profissionais quanto nas usuárias. Para os(as) profissionais, lidar com os medos das usuárias significa também lidar com os seus próprios medos ${ }^{22}$.

$\mathrm{O}$ não dito frenteà importância do HIV/aids como epidemia, além de negar a autonomia das mulheres, retarda a construção da noção de vulnerabilidade pelas mesmas, ao tempo em que possibilita às(aos) profissionais permanecerem num espaço de conforto, já que se protegem do contato cotidiano com uma realidade conflitantequenão escolheclasse, cor, sexo enem religião. Assim, homens e mulheres profissionais são tão vulneráveis quanto as usuárias dos serviços, pois, embora tenham como diferencial condições objetivas que lhes permitem 0 acesso à informação e à escolha, nem sempre esses aspectos são incorporados no que diz respeito à prevenção da infecção pelo HIV, sempretemi da e evitada como conteúdo na concretude das práticas de saúde.

Como informado anteriormente, o Ministé rio da Saúde recomenda o aconsel hamento tanto précomo pós-teste, independentementederesultado positivo ou negativo ${ }^{2}$. Resultados negativos e ações desenvolvidas na rede básica devem ser facilitadores e geradores de espaço para aconseIhamento. Ao se perder a oportunidade de realizá-lo, propicia-sea reprodução da idéia de invulnerabilidade das mulheres, tornando-as mais vulneráveis, na medida em que as mantêm distantes da compreensão dos mecanismos envolvidos nessa questão, negando-se a possibilidade de construir autonomia e empoderamento para adoção de medidas de proteção contra a infecção. Ao não se perceber vulnerável, a mulher mantém os mesmos comportamentos e práticas sexuais, mesmo após o contato com o serviço de saúde.

\section{Valores e crenças \\ que dificultam a prática da integralidade}

A atitude dos (as) profissionais revelada nas respostas das mulheres frente à experiência vivenciada por ocasião do exameanti-HIV no prénatal e na maternidade se sustenta ideologicamente em três pilares, originários de modelos estruturantes das relações, todos dificultando práticas na perspectiva da integralidade: 
(1) 0 modelo de atenção à saúde, fragmentário, tecnicista, patologizante e dirigido a queixas em detrimento de uma visão de saúde desarticulada da ausência de doença. I sso faz com que, em espaços de saúdenão especializados em HIV/ aids, a atenção ganhe importância apenas quando a infecção se instal $a^{23}$. N esse modelo de atenção, a conformação dos serviços de saúde dificulta a percepção das necessidades dos(as) usuários(as), pois nem sempre as situações vivenciadas pelas pessoas se expressam como demandas objetivas aos serviços de saúde e esses precisam estar abertos para que essas se manifestem explicitamente. $\mathrm{Na}$ organização dos serviços, predomina limitação de acesso aos cuidados, ações fe chadas à expressão dos(das) usuários(as), relações autoritárias, superficiais e hierarquizantes entre profissionais e sujeitos do cuidado, centradas em mecanismos científicos de identificação de problemas, que excluem as experiências dos(as) usuários(as). Assim, as práticas profissionais permanecem direcionadas aos aspectos biológicos dos indivíduos, desvinculando o processo de saúde-doença do contexto biopsicossocial no qual estão inseridos ${ }^{24}$;

(2) 0 modo como a sociedade incorpora 0 papel social da mulher, centrado na reprodução, amor romântico efidelidade como protetores de males sociais, dificultando a percepção de vulnerabilidade e o empoderamento feminino ${ }^{8}$. A naturalização da função social da mulher como re produtora é também internalizada pela mesma, queassume responsabilidade pela vida e pela saúde do(a) filho(a), constituindo desde então significados de maternidade que impedem questionamentos isentos de culpa, afastando de si a possibilidade de recusa frente a qualquer procedimento técnico, justificados pela proteção da criança. Isso é cotidianamente reproduzido pelos(as) profissionais de saúde, cuja identidade de gênero é construída socialmente segundo o mesmo re ferencial de mulher/mãe. Por outro lado, o exercício da função materna imprime responsabilidades com a vida que é gerada, tanto por parte dos(das) profissionais como por parte das muIheres. Diálogo, escuta eesclarecimentos possibilitam minimizar dúvidas e iniciar processos reflexivos que auxiliam na tomada de decisão e, no caso específico, espera-se quea decisão seja favorável à proteção da criança. Não obstante, deve ocorrer com suporte emocional, social e técnico à mulher, resguardando-se seus direitos como cidadã;

(3) 0 modo como o HIV/aids está representado no imaginário social, como doença do(a) outro (a), estigmatizante e carregada de preconceitos e dilemas morai $s^{24,25}$.

Estudando os dilemas morais envolvidos na oferta do teste rápido a gestantes em trabalho de parto, Israel ${ }^{21}$ verificou que os(as) profissionais revelaram se sentir despreparados(as) para comunicar um resultado positivo, pois o seu discurso não convencia nem a eles(as) próprios(as). 0 sentimento vivenciado édetensão eansiedade, pois não sabem exatamente como agir nesse momento. Consideram também a necessidade de capacitação e apoio psicológico para os(as) profissionais(as), bem como a atenção multiprofissional, na tentativa de facilitar a comunicação do diagnóstico, por exemplo.

Dessa maneira, faz-se necessário garantir e respeitar o direito das mulheres de exercer escoIhas conscientes no que diz respeito ao seu corpo e à sua saúde, bem como à de seu filho. Para tanto, éindispensável fornecer-Ihes informações claras e objetivas sobre todos os procedimentos necessários à proteção da sua saúde e da criança, levando-seem consideração o seu nível de entendimento, o contexto social no qual está inserida e os conhecimentos prévios que dispõe com relação à infecção.

Em síntese, a análise dos depoimentos das mulheres participantes do estudo revela que 0 exame anti-HIV está incorporado na rotina da prática clínica, perdendo não somente a sua especificidade mas, sobretudo, negando o direito da mulher em conhecer a importância do exame no tocante a ela eà criança, de modo a construir um posicionamento sobre a realização do mesmo. Confrontando os depoimentos das mulheres com teste rápido positivo, vê-se que, ainda quando informadas, as mulheres não são aconselhadas, seja no pré-natal, no trabal ho de parto ou puerpério, contrariando o que é defendido enfaticamente pelo Ministério da Saúde ${ }^{2}$ como direito das mulheres e obrigação profissional.

Concorre para a dificuldade do aconselhamento o despreparo profissional, que resulta tanto do processo de formação acadêmica, norteada pelo modelo clínico, quanto da falta de reflexão sobre suas práticas e sobre a necessidade de incluir a perspectiva da integralidade do cuidado.

No tocante ao exame por ocasião do trabaIho de parto, a dor e a fragilidade emocional, comumente presentes, podem criar obstáculos à realização do aconselhamento. Colabora para isso o pouco tempo disponível às(aos) profissionais nessa fase para abordar a complexa temática do HIV/aids. Porém, em outros momentos, nos quais se dispõe de maior tempo para o con- 
tato com a mulher, como no pré-natal e no puerpério, 0 aconsel hamento também não aconteceu, revelando o distanciamento dos(as) profissionais diante do problema.

As relações desiguais entre profissionais de saúde e sujeitos do cuidado dificultam o estabe lecimento deacolhimento evínculo, fazendo com que as condutas sejam limitadas a procedimentos técnicos que visam impedir a transmissão vertical do vírus HIV.

0 silêncio dos(das) profissionais diante do HIV/aids permitequese protejam deassumir responsabilidades frente à complexidade do fenômeno HIV/aids, retardando o enfrentamento do problema e a percepção de vulnerabilidade pelas mulheres, o que constitui obstáculo à integralidade do cuidado. Isto mantém as mulheres distantes da reflexão eda possibilidade de negociar com o(s) parceiro(s) práticas sexuais protegidas, mesmo após o contato com o serviço de saúde.

A ausência de aconselhamento e as orientações superficiais em torno do examerevelam que a incorporação dos exames anti-HIV na prática clínica deu-sesegundo o modelo de atenção fragmentário, perdendo sua especificidadeno tocante aos direitos da mulher em participar de modo consciente nos processos decisórios. Os serviços precisam estar abertos para que as experiências das usuárias se traduzam em demandas para os serviços de saúde, permitindo conjugar as necessidade das mulheres com as necessidades da criança, além de contribuir para a redução da vulnerabilidade das mulheres ao HIV/aids. Coelho, na revisão final e na metodologia. 


\section{Referências}

1. Brito AM, Castilho EA, Szwarcwald CL. Aids e infecção pelo HIV no Brasil: uma epidemia multifacetada. Rev. Soc. Bras. Med. Trop. [periódico na Internet] 2001 [acessado 2004 out 20]; 34(2):[cerca de 12 p.] Disponível em: http://www.scielo.br/pdf/ rsbmt/v34n2/a10v34n2.pdf

2. Brasil. M inistério da Saúde. Projeto Nascer. Brasília: Coordenação Nacional de DST e Aids; 2003.

3. Bahia. Secretaria da Saúde. Aconselhamento na pre venção de DST/HIV/aids. Bahia: Centro de Testagem e Aconselhamento Salvador; 2006.

4. Mattos RA. Os sentidos da integralidade: algumas reflexões acerca de valores que merecem ser defendidos. In: Pinheiro R, M attos RP, organizadores. Os sentidos da integralidade na atenção e no cuidado à saúde. Rio de Janeiro: IM S-UERJ/ABRASCO; 2001. p. 39-64.

5. Pinheiro R, Mattos RA. Os sentidos da integralidade na atenção e no cuidado à saúde. Rio de Janeiro: IM S-UERJ/ABRASCO; 2001.

6. Camargo JR, Kenneth $R$. Um ensaio sobre a (in)definição de integralidade. In: Pinheiro R, Mattos R, Kenneth R, Camargo JR, organizadores. Construção da Integralidade: cotidiano, saberes e práticas em saúde. Rio de Janeiro: IMS-UERJ/ABRASCO; 2003. p. 35-43.

7. Scott J. Gender: a useful category of historical analysis. In: Scott J, editor. Gender and the Politics of H istory. New York: Columbia University Press; 1988.

8. Nunes SA. A medicina social e a questão feminina. PHISYS (Rio J) 1991:1(1):49-76.

9. Brasil. M inistério da Saúde. Política nacional de atenção integral à saúde da mulher: princípios e diretrizes. Brasília: M inistério da Saúde; 2004.

10. Brasil. Ministério da Saúde. Assistência integral à saúde da mulher: bases de ação programática. Brasília: Centro de Documentação do M inistério da Saúde; 1984.

11. Coelho EAC, Oliveira JF, Almeida MS, Silva CTO, Sena VC. Integralidade no cuidado à saúde da muIher: limites e possibilidades na atenção básica, 2007. Salvador: Escola de Enfermagem, Universidade Federal da Bahia; 2005. [relatório técnico CNPQ]

12. Fiorin JL. Linguagem e ideologia. 6a ed. São Paulo: Ática; 2003.

13. Ribeiro DC. Autonomia: viver a própria vida e morrer a própria morte. Cad Saude Publica 2006; 22(8):1749-1754.

14. Foucault M. Microfísica do poder. 13a ed. Rio de Janeiro: Graal; 2001.

15. Brasil. Ministério da Saúde. Portaria no 675/GM de 30 de março de 2006. Aprova carta dos direitos dos usuários da saúde, que consolida os direitos e deveres do exercício da cidadania de saúde em todo o país. [acessado 2006 out 15]:[cerca de 7 p.] Disponível em: http://www.saude.gov.br
16. Feliciano KVO, Kóvacs MH. As necessidades comunicacionais das práticas educativas na prevenção da transmissão materno-infantil do HIV. Rev. Bras. Saude M ater. Infant. [periódico na Internet] 2003 [acessado 2005 jul 03];3(4):[cerca de 9 p.]. Disponível em: http://www.scielo.br/pdf/rbsmi/v3n4/18884.pdf

17. Remor EA. Abordagem psicológica da aids através do enfoque cognitivo-comportamental. Psicol. Refl. Crít. [periódico na Internet].1999 [acessado $2006 \mathrm{dez}$ 03];12(1):[cerca de 14 p.]. Disponível em: http:// www.scielo.br/scielo.php?script=sci_arttext\& pid=S0102-79721999000100006\&lng=en\&nrm=iso

18. Pereira MLD. "Ser mãe" e "estar com aids": o revivescimento do pecado original [dissertação]. São Paulo (SP): Escola de Enfermagem, Universidade de São Paulo; 1997.

19. Paiva MS. Vivenciando a gravidez e experienciando a soropositividade para HIV [tese]. São Paulo (SP): Escola de Enfermagem, Universidade de São Paulo; 2000.

20. Badinter E. U m amor conquistado: o mito do amor materno. 8a ed. Rio de Janeiro: Nova Fronteira; 1985.

21. Knauth DR. Subjetividade feminina e soropositividade. In: Barbosa RM, Parker R, organizadores. Sexualidades pelo avesso: direitos, identidade e poder. São Paulo: Ed. 34; Rio de Janeiro: IM S-UERJ; 1999. p. $122-135$

22. Israel GR. Como é que eu vou dizer pra gestante? Dilemas M orais da oferta do teste anti-HIV a gestantes em trabalho de parto: uma contribuição da bioética [dissertação]. Rio de Janeiro (RJ): Fundação Oswaldo Cruz, Escola Nacional de Saúde Publica; 2002.

23. Lefevre F, Lefevre, AM C. Promoção de Saúde: a negação da negação. Rio de Janeiro: Vieira \& Lent; 2004.

24. Mandú ENT. Intersubjetividade na qualificação do cuidado em saúde. Rev. Latino-am Enfermagem 2004;12(4):665-675.

25. Costa C, Lima ML. O papel do amor na percepção de invulnerabilidade à Sida. Psicologia 1998; XII(1):41-62.

Artigo apresentado em 21/06/2007

Aprovado em 24/07/2007

Versão final apresentada em 30/08/2007 